This is the accepted manuscript of the article, which has been published in Kaunisto M., Höglund M. \& Rickman P. (eds) Changing Structures: Studies in constructions and complementation. Amsterdam: John Benjamins.

Studies in Language Companion Series no. 195. ISBN: 978-90-272-0054-9. ISSN: 0165-7763. http://dx.doi.org/10.1075/slcs.195.05ric

\title{
Aspects of the Use of the Transitive into -ing Pattern in New Zealand
}

\section{English $^{1}$}

Paul Rickman and Mark Kaunisto

University of Tampere

This chapter investigates the use of the transitive into -ing pattern in one of the world's youngest dialects of English, New Zealand English (NZE). We draw on evidence collected from a diachronic NZE corpus of newspaper English, which comprises 100 million words from the years 1995-98 and 2010-12. We categorise the matrix verbs according to semantic orientation, and provide comment on any change evident between the two time-frames of the corpus, and we identify several previously undocumented matrix verbs in this pattern. Comparison is drawn to American English in an attempt to determine similarities in the use of this surprisingly productive pattern.

Keywords: New Zealand English, complementation, transitive into -ing pattern, corpus linguistics

\footnotetext{
1 The authors would like to thank the audience of the 2015 Symposium on Complementation, held at the University of Tampere in honour of Professor Juhani Rudanko. Thanks must also go to our two anonymous reviewers, whose suggestions have helped to improve the present work. We would also like to take this opportunity to acknowledge the scholarly achievements of Professor Rudanko, without which the present paper would not have been written.
} 


\section{Introduction}

The transitive into -ing pattern, exemplified by the sentence Philip tricked Phyllis into paying for dinner, has been given a thorough treatment in recent years (see, e.g. Davies 2012; Kim \& Davies 2016; Rudanko 2000; 2002; 2005; 2006; 2011; 2015a; 2015b; Rudanko \& Luodes 2005; Wulff et al. 2007). ${ }^{2}$ This surge in attention parallels a rise in the general frequency of the pattern in the main varieties of English; something that has been convincingly demonstrated in the literature (see, e.g. Rudanko 2005, and Davies 2012 for figures). Despite all the recent coverage, the usage of the pattern in the young dialect of New Zealand English remains, to the best of our knowledge, unexplored. Should the best of our knowledge prove faulty, however, the diachronic approach afforded by a corpus created specifically for studies in NZE requiring large amounts of data, such as the present chapter, will at least offer new insights into the use of the transitive into -ing pattern in this lesser studied variety of English.

With this study we aim to address the questions of how the frequency in NZE generally compares to other dialects; whether there is any apparent change in the qualitative or quantitative uses of the pattern in NZE over the time frame investigated, and whether NZE shows any innovative aspects of its use. With regard to the last point, the expectation that some kind of

\footnotetext{
${ }^{2}$ As regards terminology, here we use 'transitive into -ing', as coined by Juhani Rudanko
} 
innovative usage will be found almost goes without saying, as each of the southern hemisphere Englishes is well known for lexical idiosyncrasies (Turner 1966: 112ff.; Bauer 1994; Hay et al. 2008: 65ff.), and NZE speakers are almost certain to add some local flavour to such a productive pattern.

This chapter is structured as follows: Section 2 introduces the pattern, covers the necessary theoretical aspects of transitive into -ing, and discusses the relevant points that have arisen from earlier research. Section 3 presents the corpus used in this study and methodological issues; Section 4 comprises the results and discussion, and Section 5 provides the summary and concluding remarks.

\section{Background and earlier research}

As earlier research has noted, a compelling property of the pattern is its apparent ability to provide fertile ground for new and innovative language use, and the array of matrix verbs documented with the transitive into -ing pattern is striking, to say the least. The following example, taken from the Corpus of New Zealand Newspaper English (CNZNE), illustrates the pattern.

(1) They force the roading authorities into providing expensive new motorways. (CNZNE Dominion 1995) 
The pattern manifests certain syntactic and semantic properties that require discussion at this point. Syntactically, it should be noted that in sentence (1), the matrix verb force selects three arguments: the higher subject NP, the higher object NP, and the lower clause introduced by the preposition into. The lower clause contains a null subject NP, an understood argument, which, in an expanded syntactic representation, would be represented by the null element PRO. The postulation of a null subject, while not uncontroversial, is in accordance with much of the literature on argument structure today, and is found in recent mainstream, influential grammars of English, as this excerpt from Huddleston \& Pullum (2002: 65) shows: “[m]ost non-finite clauses have no overt subject, but the interpretation of the clause requires that an understood subject be retrieved from the linguistic or non-linguistic context” (see also Brinton and Brinton 2010: 275). PRO obtains its reference from the object of the higher clause, the roading authorities, and the sentence, therefore, is one of object control.

Verbs occurring in this pattern have been found to co-occur in some other patterns (Rudanko 2006; Kim \& Davies 2016), the main two being the $\mathrm{V}+\mathrm{NP}+$ to-infinitive pattern, which hosts three-argument verbs such as force, persuade and pressure, as in They force the roading authorities to provide expensive new motorways; and the $\mathrm{V}+\mathrm{NP}$ pattern, which hosts two-argument verbs such as fool, manoeuvre and tempt, as in They fool the roading authorities. The third and less central pattern likewise hosts two- 
argument verbs, but in this case the second argument is not of the same semantic type as the previous pattern. The difference between the semantic roles of the NP object permitted with verbs like fool/manoeuvre/tempt versus those permitted with verbs like talk, is shown by comparing the awkward sounding (?)they talked the roading authorities with the more acceptable they talked business. Verbs such as talk form the third "very limited set of verbs” (Rudanko 2006: 315).

Semantically, it is important to note that the arguments of sentence (1) are assigned the semantic roles of Agent, Patient, and Goal, for the higher subject, higher object, and lower clause, respectively. Examples of superficially similar patterns are plentiful in the data, such as sentence (2); these do not fit the bill semantically or syntactically: the semantic role of the higher object has to be seen as Instrument, rather than Patient; and the understood subject of the lower clause obtains its reference from the subject of the higher clause, making this a case of subject, rather than object control. Tokens of this type fall outside the scope of the present study.

(2) She had put her life into building the bush reserve. (CNZNE Timaru Herald 1997)

A connection between the transitive into -ing pattern and the Construction Grammar framework (Goldberg 1995) has been postulated in the literature; the pattern in this context is seen as a subtype of the caused motion 
construction. This helps to explain why so many unusual matrix verbs are so readily used in this pattern, and how speakers are able to understand the meaning without difficulty (for the original proposal of this, see Rudanko 2000: 81ff.; and for a recent detailed argument for the caused motion subtype, see Kim \& Davies 2016). While we recognise the significance of the Construction Grammar approach, it will not be a focus of this analysis.

The history of the pattern has been traced, with the help of large historical corpora. Using the Corpus of Historical American English (COHA), Davies (2012) provides a timeline for the development in AmE, and suggests that the pattern began life as an analogy of the into NP pattern, with the strongly nominal verb being first entering into that pattern, as in somehow I inadvertently willed it into being, and providing a foothold for other verbs. Davies argues that "[r]ather than have the construction created “ex nihilo”, it apparently started where [V NP into V -ing] would be least noticeable-where [into V-ing] could also be analysed as a noun, as with the pre-existing [into N]. And then once the [into V-ing] construction was firmly "established" in about the 1850s, the percentage of being decreased markedly” (Davies 2012: 166). Rudanko (2015a) traces the development in BrE using the Corpus of Late Modern English Texts (CLMET) version 3.0, and finds numerous examples of the fully fledged transitive into -ing appearing as early as the mid $18^{\text {th }}$ century, along with a few of the into being examples, so it seems clear that the pattern was already firmly established in 
BrE prior to the $19^{\text {th }}$ century. This supports earlier work by Rudanko on the history of the pattern in BrE (e.g. Rudanko 2000).

It has also been observed that verbs occurring in the transitive into ing pattern express negative causation, and that the construction has a negative semantic prosody. Wierzbicka (1998: 125) stated that "the set of main verbs that can be used in this construction is quite limited and gives a clear clue to this construction's meaning. Thus, one can not only "talk" someone "into" doing something, but also "trick" them, "manoeuver" them, or "push" them. On the other hand, one cannot "encourage" or "induce" someone "into" doing anything. [...] the into construction takes verbs that either imply, or are at least compatible with, the idea of manipulation (tricking, manoeuvring, and the like)” (see also Hunston and Francis 2000: 102 on this point). On the other hand, Rudanko (2006), citing the influence of the Great Complement Shift (Rohdenburg 2006) - a major feature of which sees -ing complements spreading at the expense of to-infinitive complements - points out a number of verbs of unflavoured, rather than negative, causation that are found in the pattern. The argument cites the verbs impel, induce, influence, lead, motivate, prompt and stimulate, all of which are also compatible with the to-infinitive complement (Kim \& Davies 2016: $25 f$ also address this issue).

Verbs found to occur in the pattern have been categorised under various different semantic groups by different authors. One such grouping, 
comprising seven categories, is given below, with example verbs provided in italics.

Deceiving or tricking - deceive, trick, bamboozle, con

Forcing or pressuring - force, pressure, arm-twist, coerce

Bullying or frightening - bully, frighten, harass, panic

Verbally persuading - cajole, inveigle, persuade, sweet-talk

Luring or tempting - lure, tempt, entice

Coaxing or stimulating - coax, stimulate, prod, stir

Other - annoy, bounce, hijack, rush (adapted from Rudanko 2000: 83)

With regard to the semantics of the matrix verb, it has been suggested that there is variation to be found between $\mathrm{BrE}$ and $\mathrm{AmE}$ in the type of verb used most frequently with the transitive into -ing. Wulff et al. (2007) suggest that BrE speakers tend to favour verbs denoting physical force, such as force, bully and push, while AmE speakers lean towards more orally persuasive verbs, such as talk, persuade and coerce. This suggestion, based on the results of statistical analyses of newspaper data, has since been reinforced by Kim \& Davies (2016), on the basis of more stratified corpora. 
We close this section with a brief outline of the target dialect of this study. ${ }^{3}$ As far as native speaker varieties of English are concerned, New Zealand English is one of the world's youngest, with the formation period 1840-1880 (Trudgill et al. 2000). ${ }^{4}$ It was during this time that settlers, mainly European, the largest single group of whom embarked in various parts of England, arrived in New Zealand in significant numbers. The large influx was due mainly to settlement schemes, and was additionally helped along by the discovery of gold. Prior to this, New Zealand was populated by fewer than 100,000 Māori and little more than several hundred Europeans. ${ }^{5}$ From 1840 then, new dialect formation processes began to take place (Gordon et al. 2004; Trudgill 2004), and by the early 20th century a distinctive new dialect was emerging, and various, mainly accent-related, aspects of it were being commented on, often unfavourably, in newspapers and other forums (for a good summary of early attitudes to NZE, see Gordon and Abell 1990).

The phonological and phonetic features of NZE have received much attention since those early years, but it has only been in recent decades that NZE has been seriously examined with the aim of documenting any

\footnotetext{
3 The present chapter represents part of a larger research project being carried out by the first author into various aspects of complementation in NZE. The aim is to document areas in which NZE differs from other varieties of English in this respect, and to discern to what extent, if at all, the phenomenon of colonial lag (Marckwardt 1958: 80; Görlach 1987; Hundt 2009) is relevant.

4 Compare Australian English (1800-1840), and South African English (1820-1860) (Trudgill et al. 2000: 302)

${ }^{5}$ Precise figures are not available for the Māori population, but Belich (1996: 178) estimates the number to have been around 86,000 in 1769, the year when Europeans first made landfall, and around 70,000 in 1840. As for Europeans, the same source (ibid.: 198) states that they numbered around 300 in 1830, and 2,000 in 1840.
} 
distinguishing grammatical features, and it is on this area that the present chapter seeks to shed further light. The nature of the pattern also inevitably takes us across the borders of the fields of vocabulary and word-formation areas in which NZE creativity, to repeat a point made in the introduction, is known to excel.

The following section continues by outlining the practical and methodological aspects of the study, and discussing the corpus that provided the data.

\section{Data and methods}

Our data come from the recently compiled Corpus of New Zealand Newspaper English (CNZNE), a 100 million word, part of speech tagged corpus comprising two sub-sections, 1995-98 (42.6 million words), and 2010-12 (58.5 million words). ${ }^{6}$ Material from a total of 13 metropolitan and provincial newspapers contributes to the total word count. The 1995-98 subsection is structured so as to allow comparison to the British National Corpus (BNC) newspaper sub-section (9,412,174 words). A detailed account of the compilation process of the CNZNE can be found in Rickman (forthcoming), but a few details here are in order.

\footnotetext{
${ }^{6}$ The CNZNE was compiled by the first author of the present paper. At the time of writing, it is not freely available.
} 
The CNZNE was compiled using material from the archives of Fairfax Media, accessed via The Knowledge Basket news and information archive service. ${ }^{7}$ Fairfax is one of the largest media conglomerates in Australasia, and, within New Zealand, it controls publications that span the length of the country. In compiling the corpus, care was taken to ensure that major metropolitan newspapers from as many of the main centres as possible were included (New Zealand's four main centres ${ }^{8}$ are traditionally understood as being Auckland, the capital Wellington, Christchurch and Dunedin), as well as provincial papers from as many different regions of the country as possible. $^{9}$ The obvious reason for this is that while it is generally acknowledged that NZE is a great deal more homogeneous than BrE and AmE, there is still known to be some regional variation (Turner 1966: 163ff.; Bauer \& Bauer 2000; Hay et al. 2008: 95ff.; Calude \& James 2011).

As well as texts from all the usual newspaper sub-genres, material obtained from the Fairfax archive also includes service information. Macalister (2001: 37) discusses service information in newspapers, defining it as "lists - sports results, tv programmes, share prices, weather forecasts, and so on”. He chose to exclude it from his corpora, and the same has been

\footnotetext{
${ }^{7}$ www.knowledge-basket.co.nz

${ }^{8}$ Many thanks to an anonymous reviewer, who pointed out that the comparatively smaller cities of Hamilton and Tauranga are now seen by Radio New Zealand and Television New Zealand as main centres, as they have been included in weather forecasts of the main centres for at least a decade now. Thus the 'four main centres' notion may be a thing of the past. It is still in use, however, as can be seen on the pages of the Government-managed online encyclopedia of New Zealand, Te Ara (http://www.teara.govt.nz), and we continue to use the term here.

${ }^{9}$ Rickman (forthcoming) also addresses the issue of multiple versions of a single article that can surface among the various publications under single ownership, like the publications under Fairfax, and the problems this causes in corpus compilation.
} 
done with the CNZNE, on the grounds that it does not help all that much in giving a clear picture of the aspects of NZE under investigation in the research project that the corpus was compiled for.

Naturally, corpus size is an all-important factor with a study of this type, and the entire 100 million word corpus was used. By today's standards, however, even 100 million words, for some research purposes, lies towards the more modest end of the scale, so in order to ensure that we were getting all that the corpus had to offer, we opted to use the simple search string [into *ing], using the concordancing software AntConc 3.2.4w, and then manually sort the relevant tokens from the roughly 5,600 total hits. The main reason for this all-inclusive approach is that, as is well known, no corpus tagging software can provide 100 per cent accurate results, and it was noticed during the preliminary search phase of this project that a search string designed to find words tagged as verbs followed by 0-4 intervening words, followed by into $\mathrm{v}_{-}{ }^{*}$ ing, for example, was not going to achieve perfect recall.

Furthermore, it was noted by Rudanko (2015b: 81ff) as part of his search for what he terms "radically innovative" matrix verbs, that words not traditionally recognised as performing a verbal function (i.e. words not listed as verbs in the OED, according to Rudanko's criteria) may nonetheless function as matrix verbs in the transitive into -ing pattern. Therefore, a search string aimed at identifying verbs may well miss all such 
radically innovative examples. With our aim of identifying innovative NZE usage, it is of course vital to retrieve all such tokens.

The coordination of matrix verbs, as in parents have to push and cajole their children into doing their homework, is reasonably common in the data, and needs to be resolved in a systematic way. We chose not to record both verbs occurring in such structures, but rather to follow Rudanko (2005: 175) in recording only the rightmost verb, in this case cajole, due to its proximity to the complement. Only in the case of established verbal units, such as name and shame, which occurs once in our data, were the verbs not separated; these were recorded as one verb.

Although the connection between the preposition and the -ing clause is tight, it is nonetheless possible to find material inserted here, and, in addition to the primary search string given above, additional searches were run to find such tokens. Examples of the results are given below.

(3) a. ...I find myself forced into not panning Jon Bon Jovi's latest effort. (CNZNE Sunday News 1997)

b. ...the Palestinians will be pounded into basically giving up on their rights and leaving. (CNZNE Dominion Post 2011)

The most common word - and it is only ever a single word in our data occurring in this position is not, which is found eight times in the entire 
corpus. Other words in this slot include: again, almost, basically, illegally, regularly. In total 21 tokens of this type were retrieved.

One aim of this analysis is to identify new matrix verbs in the target pattern, and to this end we cross-checked our results against those of a selection of prominent sources on the same topic - Bridgeman et al. (1965), Francis et al. (1996), Kim \& Davies (2016), ${ }^{10}$ and Rudanko (2005). Any verbs not documented in any of these sources were further cross-checked against the relevant entries in the Oxford English Dictionary (OED), and the New Zealand Oxford Dictionary (NZOD). If the examples supplied in these two reference works did not include the verb used in the transitive into -ing pattern, the verb was then deemed eligible to be put forward as an example of innovative usage. The results of this process are presented in the following section, along with other results.

\section{$4 \quad$ Results}

This section presents the main observations on the uses of the transitive into -ing pattern in the two parts of the CNZNE. First we will pay attention to the overall frequencies in the use of the pattern and the most common matrix verbs used with the pattern, followed by a section observing verbs

\footnotetext{
${ }^{10}$ We would like to thank Mark Davies for giving us access to the data that he and JongBok Kim collected for their 2016 study, since only a small percentage of the large number of verbs they identified were listed in the actual paper.
} 
found in the data which have been previously unattested as selecting the complement pattern.

4.1 Type and token frequencies of the transitive into -ing pattern in the CNZNE

On the whole, the transitive into -ing pattern was quite frequent in the corpus data examined, with a total of 1,485 relevant tokens found. The token and type frequencies of the matrix verbs are given in Table 1.

Table 1. The frequencies of transitive verbs selecting into -ing complements in two sections of the Corpus of New Zealand Newspaper English (pmw = per million words).

\begin{tabular}{|l|l|}
\hline CNZNE 1995-98 (42.6 million & CNZNE 2010-12 (58.5 million \\
words) & words) \\
\hline 635 tokens (14.9 pmw) & 850 tokens (14.5 pmw) \\
\hline 134 different matrix verbs & 145 different matrix verbs \\
\hline 190 different matrix verbs in total \\
89 matrix verbs common to both sets
\end{tabular}


As can be seen in Table 1, the normalized token frequencies of the pattern in the two periods were fairly similar, amounting to 14.9 instances per million words in 1995-98, and 14.5 per million words in the 2010-12 data. The type frequencies of the relevant transitive matrix verbs in the two periods were likewise close to one another, with 134 verbs found in the earlier period, and 145 verbs found in the latter. There was some variation as regards the sets of the matrix verbs with into -ing complements in that 45 verbs were unique to the 1995-98 period, 56 verbs were unique to the $2010-12$ period, and 89 verbs were found in both sets.

Considering the normalized frequencies of the matrix verbs in the CNZNE data, some interesting observations can be made on them with regard to the findings in Davies (2012) and Rudanko (2015b). Firstly, in his study on the diachronic developments in the use of the pattern in COHA, Davies (2012) noted that in 2000-09 the normalized frequency of the pattern in the AmE data was 13.9 instances per million words, which is remarkably close to the frequency in the NZE data. Another point perhaps worth observing has to do with the slight decrease in the frequencies of the pattern in the two sets of NZE data. Although the drop in the normalized frequencies (14.9 to 14.5 instances per million words) may not be striking as such, in his study of the pattern in the TIME corpus, Rudanko (2015b: 8283) also perceives a decline in the use of the pattern from the 1990s to the 
2000s, with the 1970 s being the peak period in its popularity. ${ }^{11}$ However, examination of data with a longer time span might be needed to conclude whether there is indeed a declining trend in the frequency of the transitive into -ing pattern in NZE.

The most commonly occurring matrix verbs taking an into -ing complement were largely the same in the two sets of data. In fact, the top fifteen verbs were the same in both periods (namely bully, coax, coerce, con, draw, dupe, fool, force, lure, mislead, pressure, provoke, push, talk, and trick), with only slight differences in the order of frequency of the verbs in the two periods. Since the difference in time between the two periods studied is roughly that of half a generation, the similarity among the most prominent matrix verbs could be expected.

As regards the semantic characteristics of the verbs, the same major categories can be perceived as in the earlier studies of the pattern. There are instances where the verb involves different forms of pressure; for example, intimidation or surprise (e.g. badger, blackmail, browbeat, jolt, kickstart, panic, shock), or the use of physical force (e.g. beat, bludgeon, bulldoze, stampede, thrust). Persuasion (usually verbal) is another prominent semantic group (e.g. cajole, convince, court, flatter, seduce, smooth talk, woo), as

\footnotetext{
${ }^{11}$ Interestingly enough, the normalized frequencies of the transitive into -ing pattern in the last couple of decades of the TIME Corpus are notably higher than those found in COHA and CNZNE, as the frequencies in the TIME Corpus were 29.5 and 23.1 instances per million words in the 1990s and the 2000s, respectively (Rudanko 2015b: 82). It must be noted here that the three corpora are different as regards the text types or registers represented, and it is possible that the different frequencies observed in the TIME Corpus are reflective of the use of the pattern in magazine texts.
} 
well as deception (e.g. bamboozle, confuse, deceive, hoodwink). A less prominent semantic group in the data included words involving the idea of guidance or inspiration (e.g. coach, encourage, enthuse, inspire, guide, lead, steer, support, usher), which also serve as examples of verbs that carry a positive rather than negative sense.

\subsection{Innovative usages}

The productivity of the pattern is evident also on the basis of the findings in the CNZNE data, as altogether 19 innovative usages were found in the material, that is, 19 matrix verbs which have not been previously observed as having been used in the transitive into -ing pattern. In their study, Kim \& Davies (2016) identified 335 innovative usages of the pattern in present-day AmE and BrE corpora (the Corpus of Contemporary American English [COCA], the BNC, and the US and UK sections of the Corpus of Global Web-based English [GloWbE]) containing in total as many as 1.32 billion words. From that perspective, finding innovative usages of the pattern in the NZE data is further testimony of how productive the pattern is today.

A particularly interesting case among the 19 innovative matrix verbs is the verb monster, the single instance of which is presented in example (4):

(4) ... Mr Brownlee - who spent the week beavering away with officials while Mr Key was in Australia - had been monstered 
into bringing forward an announcement by the Beehive’s ninth floor ... (CNZNE Dominion 2011)

The use of monster as a verb is seen only in some varieties of English, and the OED and the NZOD list the verbal use with the regional label “Australian”. This verb can thus be regarded as a genuinely new entry among the verbs selecting the into -ing pattern, arising from the AusE and NZE varieties. Another verb in this respect is heavy, which is listed in the OED as a verb, but not with argument patterns that would match that of the transitive into -ing pattern. The NZOD does include the word as a transitive verb, but no example is given of the verb with an into -ing complement. The example of the verb in CNZNE is given in example (5).

(5) VEHICLE franchise war has been declared in Taranaki, with a major car manufacturer heavying its New Plymouth dealership into relinquishing an opposition franchise. (CNZNE Daily News 1997)

Of the 19 innovative matrix verbs found in the CNZNE data, three verbs comply with Rudanko’s (2015b) definition of a “radically innovative” verb, i.e. they were not listed in the OED as verbs: hard-talk, peer pressure, and turbo-shock, illustrated in examples (6a-c): 
(6) a. In a statement at James' hearing he said he was peer pressured into taking cocaine on a night out with friends and said it was a mistake. (CNZNE Waikato Times 2010)

b. The original version was popular Down Under but Sabbath apparently had to be hard-talked into playing it live because they didn't like having to use a piano and Mellotron (a type of keyboard) on stage. (CNZNE Waikato Times 2010)

c. $\quad$... the experience of being hammered for pretty much eight months in a row seems to have turbo-shocked ministers into pulling up their socks in recent weeks. (CNZNE Press 2012)

The verbs peer pressure, hard-talk, and turbo-shock can also be regarded as innovative with respect to their structural property of consisting of two parts. In the case of peer pressure and hard-talk, the verbal use is probably a result of conversion or zero-derivation from a corresponding compound noun or an adjective + noun compound, while in turbo-shock the combining form turbo is attached to the base verb shock. In fact, morphological complexity is found in half of the innovations found in the corpus, as verbs involving compounding, conversion, prefixation, or the use as a phrasal verb are seen in seven other innovations of the pattern, namely fast-track, force- 
feed, pressure-cook, stir up, re-energise, reinvigorate, and wrongfoot. Here are illustrations of these verbs:

(7) a. Fast-tracking young graduates into teaching will result in disaster for many. (CNZNE Dominion Post 2011)

b. A European political elite had force-fed nations into accepting the euro, and despite multi-lateralism, it was still a world of nation states, he said. (CNZNE Southland Times 2012)

c. ARE horses getting their jumping tickets too easily these days? Are horses being pressure-cooked into jumping? A leading trainer posed these questions this week. (CNZNE Evening Post 1996)

d. Competition is a wonderful thing for stirring up local bodies into realising on assets. (CNZNE Evening Standard 1996)

e. $\quad .$. they are designed to revitalise and re-energise mature jobless people into wanting to get back into the workforce. (CNZNE Press 2011)

f. I want us to reinvigorate our families into taking up their full responsibility for their own. (CNZNE Dominion Post 2011) 
g. So Bakugan are swamped by Gogos, who cede to Mighty Beans, whose time in the sun lasts just long enough to wrongfoot a grandparent into buying the present. ${ }^{12}$ (CNZNE Dominion Post 2011)

The structural complexity seen in connection with innovative verbs was also noted by Rudanko (2015b: 85), and it may be that the innovativeness in word-forms correlates with the colourful and figurative usage characteristic of the language in magazines and newspapers.

The CNZNE data contained a further seven innovative matrix verbs with into -ing complements. These were the verbs buoy, bustle, court, fuel, irk, link, mobilise, with examples as follows:

(8) a. It was an effort which buoyed rider David Walsh into thinking he could win his second Wellington Cup ... (CNZNE Evening Post 1996)

b. Canterbury looked a more focused unit early in the second half. Immediately from the kickoff, it bustled Southland into knocking the ball dead in goal and from the resulting drop out, hooker Malcolm Aldridge scored in the corner. (CNZNE Southland Times 1997)

\footnotetext{
${ }^{12}$ Bakugan, Gogos and Mighty Beans are brands of children's toys, and the point here is that such toys enjoy only a brief period of popularity.
} 
c. But the immigrants themselves can hardly be blamed for that. They are courted into coming here as part of our immigration policy. (CNZNE Sunday News 1996)

d. ... the story goes that the artist fell in love with a younger woman, but she did not fall in love with him. That fuelled him into painting his study of the female body with a grotesque beast lying on her stomach. (CNZNE Nelson Mail 2010)

e. A cluster of real estate signs at the eastern entrance to Kurow has irked a resident into complaining to the community board representative. (CNZNE Timaru Herald 2011)

f. Girls' clothing is more aligned with fashion trends, linking girls early into being objects of the gaze and judgements of others. (CNZNE Dominion Post 2011)

g. ... it was a matter of mobilising people into putting their concerns in writing. (CNZNE Southland Times 1997)

In some instances, the entries of the verbs in the OED and the NZOD may have included examples with into + NP or to-infinitive complements. The use of the verbs with these complements has become established before the into -ing pattern. Indeed, some of the instances of into -ing patterns in (8a-g) could be rephrased by using the other types of complements, some of them 
rather easily (e.g., an effort which buoyed rider David Walsh to think that he could win his second Wellington cup; they are courted to come here; it was a matter of mobilising people to put their concerns in writing). The $\mathrm{V}+\mathrm{NP}$ + to-infinitive pattern, as noted in Section 1, is one of the main patterns with which many transitive into -ing verbs are also compatible. ${ }^{13}$

\section{$5 \quad$ Summary and conclusion}

This paper has investigated what could be seen as one of the most productive complement patterns in current English, with the aim of documenting its use and status in NZE. The data were drawn from a diachronic corpus of newspaper English with a time frame covering the better part of the last two decades. It was found that the overall frequency of the pattern does not change much over the half generation covered by the corpus, although the later section shows slightly lower frequency than the earlier. Further research would be needed to show whether this might be linked to Rudanko's (2015b) suggestion of a decrease in the use of the transitive into -ing pattern, as shown by data from the TIME corpus. The

\footnotetext{
${ }^{13}$ We agree with an anonymous reviewer, who pointed out that it would be highly relevant to compare the frequencies of the $\mathrm{V}+\mathrm{NP}+$ to-infinitive pattern and the $\mathrm{V}+\mathrm{NP}+$ into -ing pattern in NZE, among verbs that select both. While this falls outside the scope of the present study, we can refer to an observation by Juhani Rudanko on the verb force in AmE; it was noted that the results of two separate searches in COCA point to an "overwhelming predominance of the infinitival pattern in comparison to the into -ing pattern” (2015: 72). A complete appraisal of the situation in NZE will need to wait for future research.
} 
frequencies observed here are in line with those produced by Davies (2012), with data from COHA.

The data uncovered 19 matrix verbs that were previously undocumented in the transitive into -ing pattern, and at least two of these, monster and heavy, are attributed to local NZE lexical inventiveness. Clearly we are not claiming that the appearance of these verbs in this pattern in the CNZNE material represents the very first usage, only that these are possibly the first recorded examples in a study of this type. Among many of the innovative verbs, various word formation processes were seen to be actively used, and from this point of view, complex and creative matrix verbs such as turbo-shock will no doubt continue to appear, as the combination possibilities are almost endless.

The present analysis is based on newspaper language, and admittedly, the restriction to just one text type is not ideal. It should be remembered, though, that a large number of important studies have been conducted on the basis of newspaper material, and the genre does have its advantages, not least the wealth of different subject matters covered and the fact that it reflects current trends in language use. Provided the different types of newspapers - e.g. elite, popular, etc. - are represented in a corpus, valid inferences can be drawn from the results.

On a final note, it was something of a surprise that no influence of te reo Māori was evident among the matrix verbs in our material. We were 
pleased, however, to at least come across this example of the into NP pattern from earlier years:

(9) Why, only ten years after a city's Jubilee, should the people be hakaed into another outburst, while a blank interval of forty years intervenes before the centenary celebrations? (Press 1928)

We have seen that the into NP pattern has a connection with the development of the transitive into -ing pattern, and, despite not having surfaced in our corpus data, it is quite possible that haka and/or other similar words from te reo Māori are being used in the into -ing pattern somewhere in New Zealand. Given the well-known negative attitudes towards te reo Māori during the early part of the $20^{\text {th }}$ century, it seems that the author of this example was ahead of his/her time, but that haka did not succeed in making it into the ranks of verbs used with the into -ing pattern.

\section{References}

Bauer, Laurie. 1994. English in New Zealand. In The Cambridge History of the English Language, Vol V: English in Britain and Overseas, Origins and Developments, R. W. Burchfield (ed), 382-429. Cambridge: Cambridge University Press. 
Bauer, Laurie \& Bauer, Winifred. 2000. Nova Zelandia est omnis divisa in partes tres. New Zealand English Journal 14: 7-17.

Belich, James. 1996. Making Peoples: A history of the New Zealanders from Polynesian settlement to the end of the nineteenth century. Allen Lane: The Penguin Press.

Bridgeman, Lorraine, Dillinger, Dale, Higgins, Constance, Seaman, David \& Shank, Floyd. 1965. More classes of verbs in English. Bloomington: Indiana University Linguistics Club.

Brinton, Laurel J. \& Brinton, Donna M. 2010. The Linguistic Structure of Modern English. Amsterdam and Philadephia: John Benjamins.

Calude, Andreea \& James, Paul. 2011. A diachronic corpus of New Zealand newspapers. New Zealand English Journal 25: 35-52.

Davies, Mark A. 2012. Some methodological issues related to corpus-based investigations of recent syntactic changes in English. In The Oxford Handbook of the History of English, Terttu Nevalainen \& Elizabeth Traugott (eds), 157-174. Oxford: Oxford University Press.

Francis, Gill, Hunston, Susan \& Manning, Elizabeth. 1996. Collins Cobuild Grammar Patterns 1: Verbs. London: Harper Collins.

Gordon, Elizabeth, Campbell, Lyle, Hay, Jennifer, MacLagan, Margaret, Sudbury, Andrea \& Trudgill, Peter. 2004. New Zealand English: Its Origins and Evolution. Cambridge: Cambridge University Press.

Gordon, Elizabeth \& Abell, Marcia. 1990. This objectionable colonial dialect: historical and contemporary attitudes to New Zealand speech. 
In New Zealand Ways of Speaking English, Allan Bell \& Janet Holmes (eds), 21-48. Clevedon: Multilingual Matters.

Görlach, Manfred. 1987. Colonial lag? The alleged conservative character of American English and other 'colonial' varieties. English WorldWide 8: 41-60.

Hay, Jennifer, Maclagan, Margaret \& Gordon, Elizabeth. 2008. New Zealand English. Cambridge: Cambridge University Press.

Huddleston, Rodney \& Pullum, Geoffrey. 2002. The Cambridge Grammar of the English Language. Cambridge: Cambridge University Press.

Hundt, Marianne. 2009. Colonial lag, colonial innovation or simply language change? In One Language, Two Grammars? Günter Rohdenburg \& Julia Schlüter (eds), 13-37. Cambridge: Cambridge University Press.

Hunston, Susan \& Francis, Gill. 2000. Pattern Grammar: A Corpus-Driven Approach to the Lexical Grammar of English. Amsterdam: John Benjamins.

Kim, Jong Bok \& Davies, Mark A. 2016. The into-causative construction in English: a construction-based perspective. English Language and Linguistics 20: 55-83.

Macalister, John. 2001. Introducing a New Zealand newspaper corpus. New Zealand English Journal 15: 35-41.

Marckwardt, Albert. 1958. American English. New York: Oxford University Press. 
Rickman, Paul. In press. Aspects of verb complementation in New Zealand Newspaper English. In Changing English: Global and Local Perspectives, Markku Filppula, Juhani Klemola, Anna Mauranen \& Svetlana Vetchinnikova (eds). Berlin: Mouton de Gruyter.

Rohdenburg, Günter. 2006. The Role of Functional Constraints in the Evolution of the English Complementation System. In Syntax, Style and Grammatical Norms, Christiane Dalton-Puffer, Dieter Kastovsky, Nikolaus Ritt \& Herbert Schendl (eds), 143-166. Bern: Peter Lang.

Rudanko, Juhani. 2000. Corpora and Complementation: Tracing Sentential Complementation Patterns of Nouns, Adjectives and Verbs over the Last Three Centuries. Lanham, MD: University Press of America.

Rudanko, Juhani. 2002. Complements and Constructions. Lanham, MD: University Press of America.

Rudanko, Juhani. 2005. Lexico-grammatical innovation in current British and American English: A case study on the transitive into -ing pattern with evidence from the bank of English corpus. Studia Neophilologica 77: 171-87.

Rudanko, Juhani. 2006. Emergent alternation in complement selection: the spread of the transitive 'into -ing' construction in British and American English. Journal of English Linguistics 34: 312-331.

Rudanko, Juhani. 2011. Changes in Complementation in British and American English: Corpus-based Studies on Non-finite Complements in Recent English. Basingstoke, UK: Palgrave Macmillan. 
Rudanko, Juhani. 2015a. Wheedled me into lending him my best hunter: Comparing the emergence of the transitive into -ing pattern in British and American English. In Perspectives on Complementation: Structure, Variation and Boundaries, Mikko Höglund, Paul Rickman, Juhani Rudanko \& Jukka Havu (eds), 128-140. Basingstoke, UK: Palgrave Macmillan.

Rudanko, Juhani. 2015b. Linking Form and Meaning: Studies on Selected Control Patterns in Recent English. Basingstoke, UK: Palgrave Macmillan.

Rudanko, Juhani \& Luodes, Lea. 2005. Complementation in British and American English. Lanham, MD: University Press of America.

Trudgill, Peter. 2004. New-Dialect Formation: The Inevitability of Colonial Englishes. Oxford: Oxford University Press.

Trudgill, Peter, Gordon, Elizabeth, Lewis, Gillian \& Maclagan, Margaret. 2000. Determinism in new-dialect formation and the genesis of New Zealand English. Journal of Linguistics 36: 299-318.

Turner, G. W. 1966. The English Language in Australia and New Zealand. London: Longman.

Wierzbicka, Anna. 1998. The semantics of English causative constructions in a universal-typological perspective. In The New Psychology of Language: Cognitive and Functional Approaches to Language Structure, Volume I, Tomasello, Michael (ed), 113-153. Mahwah, NJ: Lawrence Erlbaum. 
Wulff, Stefanie, Stefanowitsch, Anatol \& Gries, Stefan Th. 2007. Brutal Brits and persuasive Americans. In Aspects of Meaning Construction, Günter Radden, Klaus-Michael Köpcke, Thomas Berg and Peter Siemund (eds), 265-282. Amsterdam: John Benjamins. 